\title{
ХВИЛЕВІДНИЙ ФАЗОЗСУВНИЙ ПРИСТРІЙ ІЗ ТРЬОМА ДІАФРАГМАМИ У ДІАПАЗОНІ 5.0-8.0 ГГЦ
}

\author{
Биковський О. В. \\ (Науковий керівник Пільтяй С. I., к.т.н., доцент)
}

Національний технічний університет Украӥни «Київський політехнічний інститут ім. Ігоря Сікорського», Радіотехнічний факультет

Для покращення інформаційних параметрів сучасних антенних решіток використовують поляризатори та фазозсувачі. Фазозсувні пристрої забезпечують на виході потрібні значення фазової характеристики, поляризаційні пристрої забезпечують на виході фазовий зсув в $90^{\circ}$ Такі пристрої будуються на штирях, діафрагма, їх комбінації та інших типах неоднорідностей. Штирьові поляризаційні пристрої більше всього вживаються, коли треба отримати вузьку смугу частот [1-4]. Діафрагмові хвилевідні поляризаційні пристрої використовують, коли необхідно отримати більш ширшу робочу смугу частот [5-8]. Ще $\epsilon$ поляризаційні пристрої на основі хвилеводів, що поєднують штирі та діафрагми [9-11]. Вони дають можливість здійснювати регулювання основних характеристик [12-15]. Для проектування таких пристрої пристроїв користуються програмними пакетами HFSS та CST MS [16-17]. Тому, зараз $є$ актуальною задача створення широкосмугових поляризаційних пристроїв в радіолокаційних системах. Крім того, описані поляризатори ще використовуються у системах 5G [18-24].

За допомогою методу хвильових матриць [12, 13] були пораховані коефіцієнт відбиття та фазова характеристики. Крім того, для порівняння у програмі CST MS по методам FDTD та FEM [25-27] був розроблений та оптимізований хвилевідний фазозсувний пристрій із трьома діафрагмами (рис. 1). Діафрагми були розміщені всередині хвилеводу та розміщені на однаковій відстані від середньої діафрагми.

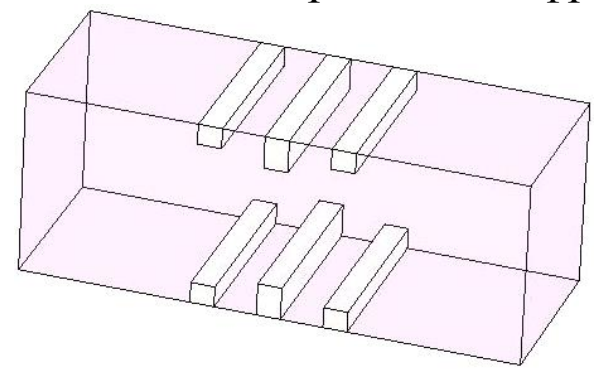

Рис. 1 - Модель хвилеводного фазозсувача із трьома діафрагмами
У діапазоні частот 5.0-8.0 ГГц були отримані фазові та узгоджувальні характеристики фазозсувача. На рис. 2 наведені фазові характеристики розробленого фазозсувача у діапазоні частот 5.5-8.5 ГГц. Можна зазначити, що фазозсувач підтримує фазу у діапазоні $90 \pm 5.0^{\circ}$ для поданого методу, $90^{\circ} \pm 4^{\circ}$ для методу FDTD та $90^{\circ} \pm 6^{\circ}$ для методу FEM.

На рис. 3 наведені узгоджувальні характеристики у робочому діапазоні частот 5.0-8.0 ГГц. 


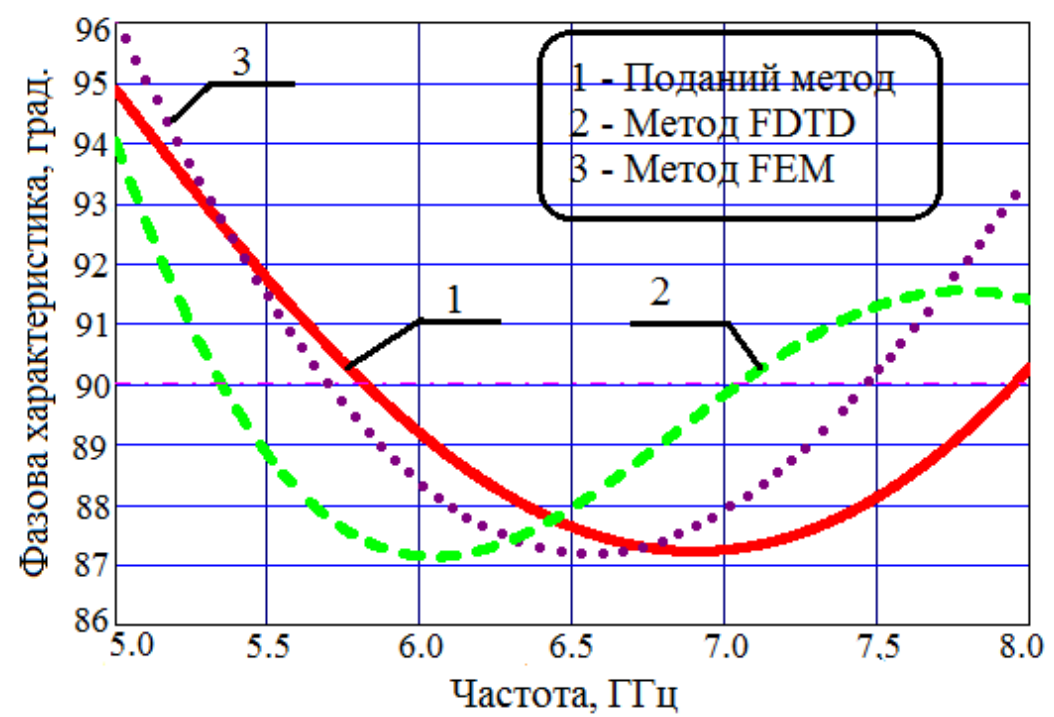

Рис. 2 - Фазова характеристика

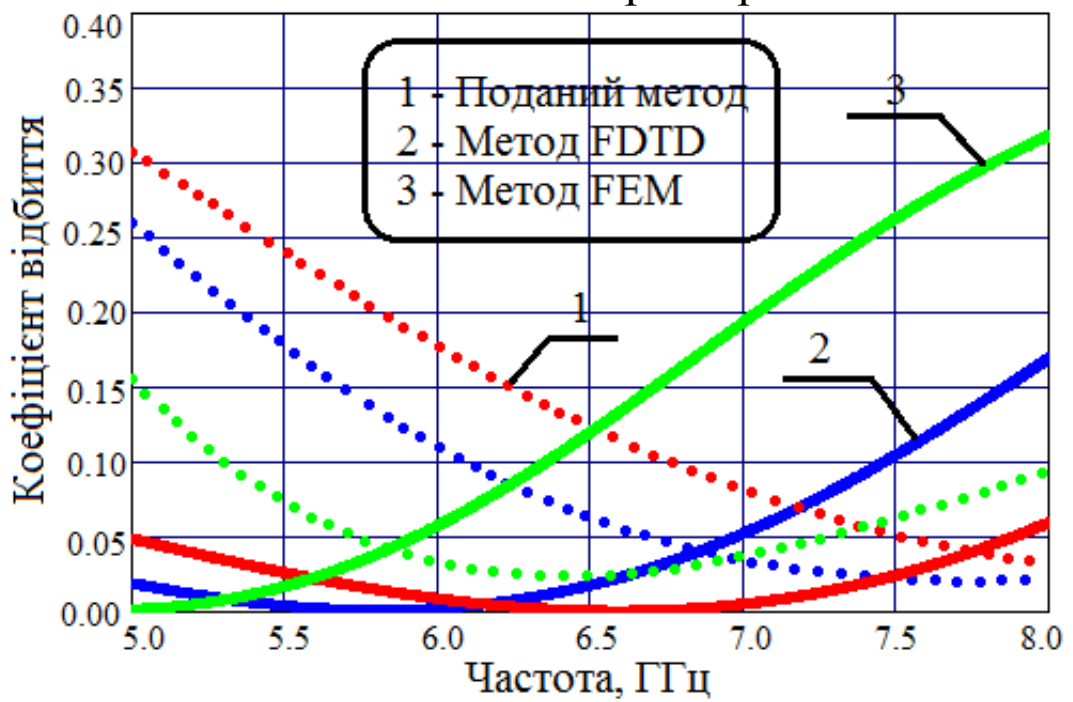

Рис. 3 - Узгоджувальна характеристика

Рис.

3. містить частотну коефіцієнта залежність відбиття розробленого фазозсувача для поданого методу, методу FDTD, методу FEM. Слід підкреслити, що максимальне значення коефіцієнта відбиття $є$ 0.31 для поданого методу, 0,26 для методу FDTD та 0.33 для методу FEM.

$\mathrm{y}$

тезі

був

досліджений

хвилевідний

фазо

зсувний пристрій iз трьома діафрагмами у робочому діапазоні 5.08.0 ГГЦ. Розроблений пристрій забезпечує фазовий зсув у діапазоні $90^{\circ} \pm 5^{\circ}$. Максимальне значення коефіцієнту

\section{відбиття} для вертикальної та горизонтальної

поляризацій становить 0,31. Отже, запропонований пристрій може використовуватися у сучасних фазованих антенних решітках.

\section{Література}

1. Dubrovka F. Circularly polarised X-band H11- and H21-modes antenna feed for monopulse autotracking ground station / F. Dubrovka, et al. // IEEE Ukrainian Microwave Week, Kharkiv, Ukraine, September 2020, pp. 196202. DOI: 10.1109/UkrMW49653.2020.9252600.

2. Piltyay S. Information resources economy in satellite systems based on new microwave polarizers with tunable posts / S. Piltyay, et al. // Path of Science. - 2020. - Vol. 6, No 11. - pp. 5001-5010. http://doi.org/10.22178/pos.64-6.

3. Bulashenko A.V. Compact waveguide polarizer with three antiphase posts / A.V. Bulashenko, et al. // Visnyk VPI. - 2020. - Vol. 5. - pp. 97-104. [In Ukrainian]. DOI: 10.31649/1997-9266-2020-151-5-97-104.

4. Bulashenko A.V. Tunable square waveguide polarizer with irises and posts / A.V. Bulashenko, et al. // Technical Engineering. - 2020. - Vol. 86, no 2. - pp. 108-116. DOI: 10.26642/ten-2020-2(86)-108-116.

5. Bulashenko A.V. Optimization of a polarizer based on a square waveguide with irises / A.V. Bulashenko, et al. // Science-Based Technologies. - 2020. - Vol. 47, No. 3. - pp. 287-297. (in Ukrainian). http://doi.org/10.18372/23105461.47.14878.

6. Bulashenko A.V. Waveguide polarizer with three irises for antennas of satellite television systems / A.V. Bulashenko, et al. // Science-Based Technologies. - 2021. - Vol. 49, No. 1. - pp. 39-48. http://doi.org/10.18372/23105461.49.15290. 


\section{IV ВНTК Радіоелектроніка у XXI столітmі}

7. Piltyay S.I. Waveguide iris polarizers for Ku-band satellite antenna feeds / S.I. Piltyay, et al. // Journal of Nano- and Electronic Physics. $\quad$ - 2020. $\quad$ - Vol. 12, No. 5. pp. 05024-1-05024-5. http://doi.org/10.21272/jnep.12(5).05024.

8. Piltyay S.I. High performance waveguide polarizer for satellite information systems / S.I. Piltyay, et al. // Bulletin of Cherkasy State Technological University. - 2020. - Vol. 4. - pp. 14-26. [In Ukrainian]. DOI: 10.24025/2306-4412.4.2020.217129.

9. Piltyay S. New tunable iris-post square waveguide polarizers for satellite information systems / S. Piltyay, et al. // IEEE 2nd International Conference on Advanced Trends in Information Theory, 25-27 November 2020, Kyiv, Ukraine, pp. 342-348. DOI: 10.1109/ATIT50783.2020.9349357.

10. Bulashenko A. Mathematical modeling of iris-post sections for waveguide filters, phase shifters and polarizers / A. Bulashenko, et al. // IEEE 2nd International Conference on Advanced Trends in Information Theory, 2527 November 2020, Kyiv, Ukraine, pp. 330-336. DOI: 10.1109/ATIT50783.2020.9349321.

11. Piltyay S. Analytical modeling and optimization of new Ku-band tunable square waveguide iris-post polarizer / S.I. Piltyay, et al. // International Journal of Numerical Modelling: Electronic Networks, Devices and Fields. - 2021. - Vol. 34, no. 4. - pp. 1-27. DOI: 10.1002/JNM.2890.

12. Bulashenko A.V. Equivalent microwave circuit technique for waveguide iris polarizers development / A.V. Bulashenko, S.I. Piltyay // Visnyk NTUU KPI Seriia - Radiotekhnika, Radioaparatobuduvannia. - 2020. - Vol. 83. pp. 17-28. http://doi.org/10.20535/RADAP.2020.83.17-28.

13. Bulashenko A.V. Wave matrix technique for waveguide iris polarizers simulation. Theory / A.V. Bulashenko, et al. // Journal of Nano- and Electronic Physics. - 2020. - Vol. 12, no. 6. - pp. 06026-1-06026-5. DOI: 10.21272/jnep.12(6).06026.

14. Bulashenko A. Analytical technique for iris polarizers development / A. Bulashenko, et al. // IEEE International Conference on Problems of Infocommunications. Science and Technology. - Kharkiv, Ukraine, 2020. pp. 471-476.

15. Piltyay S.I. Analytical synthesis of waveguide iris polarizers / S.I. Piltyay, et al. // Telecommunications and Radio Engineering. - 2020. - Vol. 79, No 18. - pp. 1579-1597. http://doi.org/10.1615/TelecomRadEng.v79.i18.10

16. Bulashenko A.V. Simulation of compact polarizers for satellite telecommunication systems with the account of thickness of irises / A.V. Bulashenko, S.I. Piltyay, I.V. Demchenko // KPI Science news. - 2021. - Vol. 1. - pp. 7-15.

17. Piltyay S.I. Compact Ku-band iris polarizers for satellite telecommunication systems / S.I. Piltyay, et al. // Telecommunications and Radio Engineering. - 2020. - Vol. 79, no. 19. - pp. $1673-1690$. DOI:10.1615/TelecomRadEng.v79.i19.10.

18. Bulashenko A. New traffic model of M2M Technology in 5G wireless sensor networks / A. Bulashenko, et al. // IEEE 2nd International Conference on Advanced Trends in Information Theory, 25-27 November 2020, Kyiv, Ukraine, pp. 125-131. http://doi.org/10.1109/ATIT50783.2020.9349305.

19. Piltyay S.I. Wireless sensor network connectivity in heterogeneous 5 G mobile systems / S.I. Piltyay, et al. // IEEE International Conference on Problems of Infocommunications. Science and Technology, Oct. 2020, Kharkiv, Ukraine, pp. 508-513.

20. Bulashenko A.V. Energy efficiency of the D2D direct connection system in 5G networks / A.V. Bulashenko, et al. // IEEE International Conference on Problems of Infocommunications. Science and Technology, Oct. 2020, Kharkiv, Ukraine, pp. 324-329.

21. Bulashenko A.V. Evaluation of D2D Communications in 5 G networks / A.V. Bulashenko // Visnyk NTUU KPI Seriia - Radiotekhnika, Radioaparatobuduvannia. - 2020. - Vol. 81. - pp. 21-29. (in Ukrainian). http://doi.org/10.20535/RADAP.2020.81.21-29.

22. Bulashenko A.V. Combined criterion for the choice of routing based on D2D technology / A.V. Bulashenko // Radio Electronics, Computer Science, Control. - 2021. - Vol. 1. - pp. 7-13. (in Ukrainian). http://doi.org/10.15588/1607-3274-2021-1-1.

23. Bulashenko A.V. Data upload system using D2D technology in the unlicensed frequency range as part of the 5G communication system / A.V. Bulashenko // Technical Engineering. - 2020. - Vol. 86, No. 2. - pp. 103-107. (in Ukrainian). http://doi.org/10.26642/ten-2020-2(86)-103-107.

24. Bulashenko A.V. Resource allocation for low-power devices of M2M technology in $5 \mathrm{G}$ networks / A.V. Bulashenko // KPI Science news. - 2020. - Vol. 3. - pp. 7-13. (In Ukrainian). http://doi.org/10.20535/kpisn.2020.3.203863.

25. Piltyay S.I. Numerical performance of FEM and FDTD methods for the simulation of waveguide polarizers / S.I. Piltyay, et al. // Visnik NTUU KPI Seriia - Radiotekhnika, Radioaparatobuduvannia. - 2021. - Vol. 84. - pp. 1121. DOI:10.20535/RADAP.2021.84.11-21.

26. Piltyay S. FDTD and FEM simulation of microwave waveguide polarizers / S. Piltyay, et al. // IEEE 2nd Int. Conf. on Advanced Trends in Information Theory, 25-27 November 2020, Kyiv, Ukraine, pp. 132-137. DOI: 10.1109/ATIT50783.2020.9349339.

27. Piltyay S. Compact polarizers for satellite information systems / S. Piltyay, et al. // IEEE International Conference on Problems of Infocommunications. Science and Technology. - Kharkiv, Ukraine, 2020. - pp. $317-322$. 